\title{
Sinorhizobium meliloti nifA mutant induces different gene expression profile from wild type in Alfalfa nodules
}

\author{
Zi Ying Gong ${ }^{1}$, Zhi Shui $\mathrm{He}^{1}$, Jia Bi Zhu' ${ }^{1}$, Guan Qiao Yu${ }^{1}$, Hua Song Zou ${ }^{1}$ \\ ${ }^{I}$ National Laboratory of Plant Molecular Genetics, Shanghai Institute of Plant Physiology and Ecology, Shanghai Institutes for \\ Biological Sciences, Chinese Academy of Sciences, Shanghai 200032, China
}

Several studies have demonstrated that the Rhizobium nifA gene is an activator of nitrogen fixation acting in nodule bacteria. To understand the effects of the Sinorhizobium meliloti nifA gene on Alfalfa, the cDNA-AFLP technique was employed to study the changes in gene expression in nifA mutant nodules. Among the approximately 3,000 transcriptderived fragments, 37 had differential expression levels. These expression levels were subsequently confirmed by reverse Northern blot and RT-polymerase chain reaction. Sequence analyses revealed that $21 \mathrm{cDNA}$ fragments corresponded to genes involved in signal communication, protein degradation, nutrient metabolism, cell growth and development.

Cell Research (2006) 16:818-829. doi:10.1038/sj.cr.7310096; published online 26 September 2006

Keywords: cDNA-AFLP, gene expression, nodule, Sinorhizobium meliloti, nifA

\section{Introduction}

Nitrogen fixation in legumes takes place in highly specialized root nodules that result from the association between Rhizobia and legume plants [1-3]. The bacteria enter the nodule via an infection thread, and then differentiate into nitrogen-fixation bacteroids, which are capable of fixing atmospheric nitrogen into ammonia that provided to the plant. In return, the host plant provides carbon and energy to the bacteroids in the form of $\mathrm{C}_{4}$-dicarboxylic acids $[4,5]$. Nodules are unique among plant organs as their development arises as a result of interactions among many cooperating plant and bacterial genes. However, at the molecular level, only a few events in the communication between bacteria and plants are understood. In plants, a set of early nodulin genes encode products that are involved in infection and nodule development. The products of late nodulin genes participate in the contribution of the endosymbiont to the specialized metabolic activity of the nodule $[6,7]$. Within bacteroids, nitrogenase synthesis (nif) and

Correspondence: Hua Song Zou

Tel: +86-21-54924166; Fax: +86-21-54924015;

E-mail: hszhou@sibs.ac.cn.

Received 15 Aug 2005; revised 8 Feb 2006; accepted 28 Feb 2006; published online 26 Sep 2006 microoxic respiration (fix) genes and an oxygen-limited condition are required for nitrogen fixation $[2,8]$.

In Sinorhizobium meliloti, the nifA gene as well as nif$H D K E$, fixABCX and fixLJ are located in a large plasmid, pSymA [9]. The fixL and fix $J$ genes encode a two-component regulatory system in which the oxygen sensor FixL transfers phosphate to the response regulator FixJ. Phosphorylated FixJ positively controls transcription of fixK and nifA $[10,11]$. FixK induces expression of fixNOQP and negatively affects expression of $n i f A$, whereas NifA is required for transcription of $f i x A B C X$, nif $N$ and $n i f B$, as well as for transcription of the nifHDK operon that encodes the subunits of the nitrogenase [12]. However, the FixL/FixJ system is not required for nifA gene expression in Bradyrhizobium japonicum [13]. In addition to nif and fix genes, NifA controls some other genes not directly involved in nitrogen fixation, such as genes related to nodulation competitiveness, rhizopine synthesis, nodule development and bacteroid persistence in S. meliloti [14].

Previous studies inferred that nifA mutants not only failed to fix nitrogen but also elicited numerous small nodules whose necrotic interior was reminiscent of a hypersensitive response characteristic of non-compatible host-pathogen interactions [3]. The nodules induced by the $S$. meliloti nifA mutant differed from those induced by wild type in that the fixation zone was less extensive and many of the cells 
interspersed within the fixation zone contained senescent bacteroids. In addition, a significantly larger senescent zone was observed in S. meliloti nifA mutant nodules [15]. We previously found that small, white and ineffective nodules were also formed in plants infected with $S$. meliloti that had been transformed with a multi-copy plasmid carrying nifHDK genes driven by a $\mathrm{P} 1$ promoter [16]. This indicated that the redundant nifHDK promoter brought about a shortage of NifA protein necessary for normal nodulation in the host plant. Thus, it is speculated that nif $A$ not only regulates nif/fix genes but also genes involved in nodule formation and maintenance. Recently, our unpublished data indicated that nif $A$ affects the nodulation on other lateral roots in split root system. However, little is known about how host genes act in response to the expression of $S$. meliloti nifA. In the present study, we compared gene expression profiles in an S. meliloti nifA mutant nodules with wild-type. We aimed to characterize the molecular events taking place during symbiotic association, and to provide new clues concerning the relationship between signaling molecules and the S. meliloti nifA gene.

\section{Materials and Methods}

\section{Bacterial strains}

The wild-type $S$. meliloti strain Rm1021 and its nifA mutant Sm1354 (nifA::Tn5) strain were used in this study [15]. Escherichia coli DH5 $\alpha$ was used for plasmid DNA transformation.

\section{Plant cultivation}

Seeds from Medicago sativa were surface sterilized, germinated and then grown in plastic barrels on nitrogen-free vermiculite. Wildtype Rm1021 and nifA mutant Sm1354 were inoculated on plants as described previously [17]. The nodules induced by Rm1021 or Sm1354 were harvested 15 and 30 days after inoculation and stored at $-70{ }^{\circ} \mathrm{C}$.

\section{cDNA-AFLP analysis}

cDNA-AFLP was carried out according to standard procedures with little modification [18]. Briefly, total RNA was extracted from the nodules 30 days after inoculation (Total RNA isolation Kit IV, Watson, China) according to the manufacturer's instructions. mRNA was purified using an mRNA isolation system (Watson, China). Double-strand cDNA was synthesized using an anchored oligo-(dT) ${ }_{18}$ primer and Superscript II RNase H reverse transcriptase (Invitrogen)

Table 1 Primers used in RT-PCR experiments for 24 TDFs

\begin{tabular}{cl}
\hline AFLP fragment No. & \multicolumn{1}{c}{ Primers } \\
\hline G3 & F: 5' ATTTATAAAGGGAGGAAG3'; R: 5'ACCATTTGTAGCAGTAGAGC3' \\
G5 & F: 5'ACCTAACAAAACCCTAGCGAGT3'; R: 5'AAGCAGAACAAAGCCAAATAAAA3' \\
G6 & F: 5'GTTGGATATGACTGAACGCCTCTA3'; R: 5'GGCCACTCTGCCACTTCAATAC3' \\
G7 & F: 5'CAACAGCCTCAGCAGAACAA3'; R: 5'GCTGGGTTTAGATACAGA3'ATCATAG3' \\
G8 & F: 5'ACTGTCTTACATTGCGGGTTTG3'; R: 5'TCAATTTGACCAGGGTGATGCT3' \\
G9 & F: 5'GACACCTTTGTGAACTTCCCCA3'; R: 5'AGATGATCTGTTTTAGCCTCCG3' \\
G10 & F: 5'CAAATCCATAACCGTAACAAGAAC3'; R: 5'CCAGATCCAGGAAAGAAGAGCC3' \\
G11 & F: 5'ACCCAGAAAAGCCGCCAAGTGT3'; R: 5'AAATAGGAGCATTCCCCAACAT3' \\
G12 & F: 5'GATCGAGATCCATGCGGG3'; R: 5'GCTCTGAATCGAAGCCCCA3' \\
G13 & F: 5'GGGCACCAGGGACTATACATAC3'; R: 5'GAAACCGACAGATCCGAAAGA3' \\
G15 & F: 5'GCTGCAGGTCGACGATTGAT3'; R: 5'GGGGAGTCTTCTTATGAGGGTTT3' \\
G16 & F: 5'TTTAGTAGTCGGGCTGTTGA3'; R: 5'ACTGCGTACCAATTCCCCTG3' \\
G17 & F: 5'CAGGTCGACGATTGATGAGT3'; R: 5'CTGCGTACCAATTCCCATAT3' \\
G19 & F: 5'GATATGGGAGGAAGGGCAAAGGG3'; R: 5'GGGGGAATTTCATTACATCACCATCTTA3' \\
G20 & F: 5'TGCTGCGGTCGACGATTGAT3'; R: 5'CGTTTTTTATATTCTCCCAA3' \\
G22 & F: 5'ATTGCAGTTGCCAGTGCATCAT3'; R: 5'CTGCAGCAAAAGGCTTGTTCTC3' \\
G23 & F: 5'CAGGCTAGAAAGAAAATGAAGATAC3'; R: 5'CTAAGATGAGGGTACTGGAGAA3' \\
G24 & F: 5'TAGTGCCCAGAAATGAAA3'; R: 5'CAAAGATTGACGATGTTCCA3' \\
G26 & F: 5'TCGCAAAGTCAAGCAGAAGA 3'; R: 5'GCGCAGGATTACTATAACCAT3' \\
G29 & F: 5'TCTCCTCACCAGGTAACCACATC3'; R: 5'ATCACCTGAAGAAAGAAAATCCC3' \\
G30 & F: 5'CAATGATAGGAAGAGCCGACAT3'; R: 5'TGGAAACAGCGAAAGTGAAATA3' \\
G31 & F: 5'CCCTATTGCGTCCTTTCTTGT3'; R: 5'ATTCGCCGTCCCAGCCTTGTC3' \\
G34 & F: 5'GGCGATAGGGTGAAACATT3'; R: 5'GCATCAGCAGCATAAAAGGA3' \\
G35 & F: 5'ATCAAAGACCACAAAATCTGAAAT3'; R: 5'AAAATATGGCTAAAGTCGCTAAGT3' \\
\hline
\end{tabular}


according to the manufacturer's protocol. The pre-amplification step for 16 cycles of polymerase chain reaction (PCR) was performed with an $E c o \mathrm{RI}+0 / \mathrm{Mse}+0$ adaptor primer combination. Pre-amplified productions were diluted 50 -fold and $5 \mu 1$ was used as template for final amplifications using $\gamma^{33}$-labeled EcoRI primer with two selective nucleotides and an $M s e I$ primer with two selective nucleotides. The obtained radioactive amplification products were separated on 5\% polyacrylamide gels and run at 90 Watts in Sequi-Gen GT nucleic acid sequencing cell (Bio-Rad) until the xylene-cyanol dye reached the $1 / 3$ position from the bottom. Gels were covered with plastic film and positionally marked before being exposed to Kodak film for 3 days.

\section{Fragment characterization}

The differentially expressed bands were individually collected as template for re-amplification with the same primers used in AFLP analysis. Re-amplified products were analyzed by agarose electrophoresis, cloned into pMD18-T vector (Takara) and sequenced. The obtained sequences were compared to nucleotide and protein sequences in publicly available databases (http://www.medicago. org/genome/blast.php).

\section{Reverse Northern hybridization}

Reverse Northern hybridization was used to confirm the differential gene expression results obtained from cDNA-AFLP. To prepare hybridization templates more conveniently, a pair of specific primers were designed according to $\mathrm{pMD} 18-\mathrm{T}$ vector sequence at cloning site (F: 5'GCG GAT AAC AAT TTC ACA CAG3'; R: 5'CCA GGG TTT TCC CAG TCAC3'). Equal volumes of PCR products (about $1 \mu \mathrm{g}$ ) were loaded into $1.5 \%$ agarose gels. DNA samples were then transferred to nylon membranes (Amersham Biosciences). Total RNA was extracted from 15- and 30-day-old nodules. Radiolabeled cDNA probes were synthesized by reverse transcription of $10 \mu \mathrm{g}$ of total RNA for $1 \mathrm{~h}$ in the presence of $100 \mu \mathrm{Ci}\left[{ }^{32} \mathrm{P}\right] \mathrm{dCTP}$ with the Superscript reverse transcriptase. Probes derived from each RNA sample were hybridized against one set of transcript-derived fragments (TDFs) obtained above. Hybridization was performed in 0.5 M Na-phosphate (pH 7.2), 1 mM EDTA, 7\% SDS buffer for $16 \mathrm{~h}$ at $65^{\circ} \mathrm{C}$, washed twice for $5 \mathrm{~min}$ with $40 \mathrm{mM} \mathrm{Na}$-phosphate $/ 1 \mathrm{mM}$ EDTA $/ 5 \%$ SDS and then washed four times for 10 min with $40 \mathrm{mM}$ Na-phosphate/1 mM EDTA/1\% SDS. Hybridization signals were observed first on Kodak X-ray film and then quantified by Dots hybridization analysis system (Tanon 2.20, China).

\section{$R T-P C R$}

To control for equal amounts and quality of RNA template, an additional RT-PCR was performed under the same conditions as PCR with specific primers based on the sequence of Ribosome large subunit gene (F: 5'ACC AGA GCC GCT AAG GTT3'; R: 5'CAG CTT ACA TAA CCG GTC $\left.3^{\prime}\right)$. The primers used for 24 cDNA TDFs are listed in Table 1.

\section{Results}

\section{Characterization of differentially expressed TDFs}

cDNA-AFLP reactions were performed with 64 combinations of EcoRI and MseI primers having two selective 3 ' terminal nucleotides. This reduced the number of fragments per fingerprint to $\sim 50$. Although the majority of

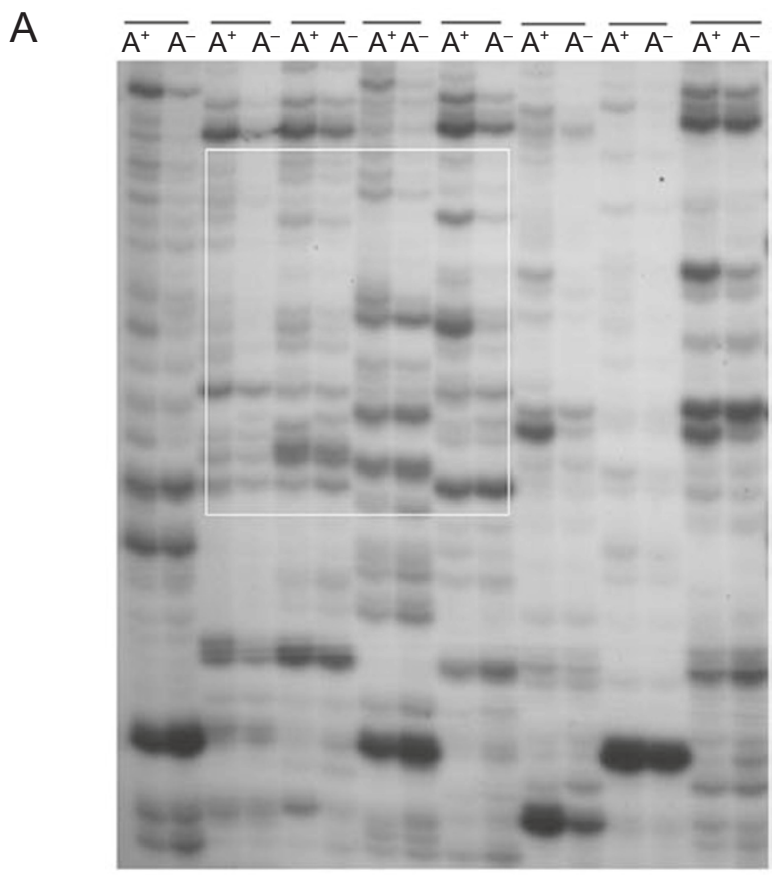

B

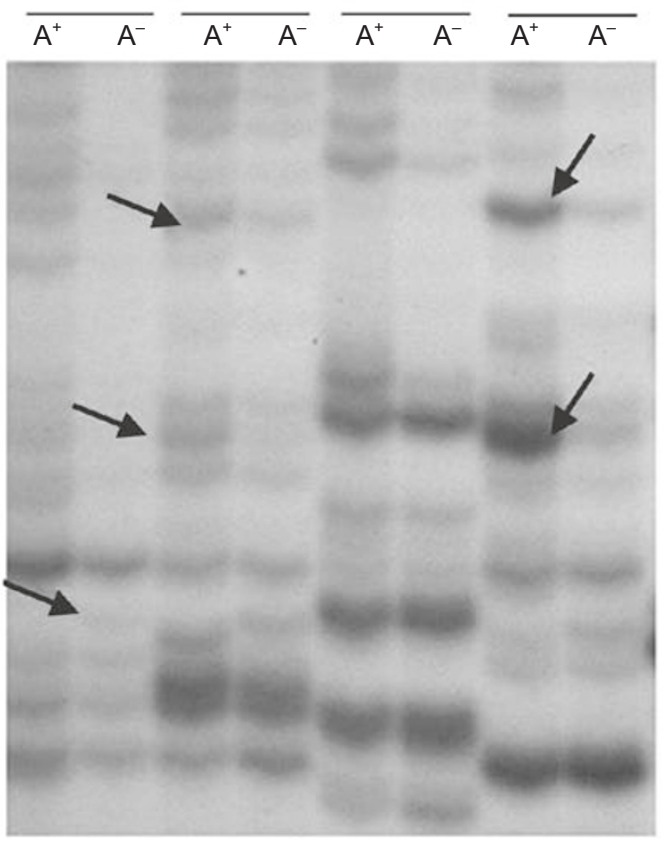

Figure 1 cDNA-AFLP display of transcripts in nodules elicited by $S$. meliloti wild-type strain Rm1021 and nifA mutant Sm1354. RNA was extracted from 30-day-old nodules induced by wild-type Rm1021 $\left(\mathrm{A}^{+}\right)$and nifA mutant Sm1354 $\left(\mathrm{A}^{-}\right)$. Lanes are in groups of two, and each group was amplified using one combination of EcoRI and MseI primers having two selective $3^{\prime}$ terminal nucleotides. (A) A selection of cDNA-AFLP display. (B) Enlarged view of the box in (A). The arrow shows the differentially expressed TDFs. 
Table 2 The EST database in GenBank showing homology with differentially expressed TDFs

\begin{tabular}{|c|c|c|c|c|c|c|}
\hline \multirow{2}{*}{$\begin{array}{c}\text { AFLP } \\
\text { fragments }\end{array}$} & \multirow{2}{*}{$\begin{array}{l}\text { Size } \\
\text { (bp) }\end{array}$} & \multirow{2}{*}{$\begin{array}{c}\text { GenBank } \\
\text { Accession No. }\end{array}$} & \multicolumn{3}{|c|}{ Homology } & \multirow[t]{2}{*}{ Score/e-value } \\
\hline & & & Accession No. & Species & Tissue type & \\
\hline G3 & 162 & DR025667 & CB827529.1 & Lotus japonicus & $\begin{array}{l}\text { Nodule library } 5 \text { and } \\
7 \text { weeks old }\end{array}$ & $32 / 1 \mathrm{e}-07$ \\
\hline $\mathrm{G} 4^{*}$ & 412 & DR159684 & BQ136242.1 & Medicago truncatula & Elicited cell culture & $210 / 2 \mathrm{e}-113$ \\
\hline $\mathrm{G} 5^{*}$ & 530 & DR159685 & CO513060.1 & Medicago sativa & Glandular trichomes & $454 / 0.0$ \\
\hline G6 & 244 & DR159686 & CO5132971 & Medicago sativa & Glandular trichomes & $229 / 5 e-125$ \\
\hline G7 & 245 & DR159687 & CO515538.1 & Medicago sativa & Glandular trichomes & $224 / 5 e-122$ \\
\hline $\mathrm{G} 8^{*}$ & 654 & DR159688 & CX550739.1 & Medicago truncatula & Roots & $459 / 0.0$ \\
\hline G9* & 593 & DR159689 & CB892042.1 & Medicago truncatula & Roots & $537 / 0.0$ \\
\hline G10* & 465 & DR159662 & CX549961.1 & Medicago truncatula & Roots & $433 / 0.0$ \\
\hline G11* & 417 & DR159663 & CX550724.1 & Medicago truncatula & Roots & $377 / 0.0$ \\
\hline G12 & 200 & DR025668 & CK550724.1 & Heterodera glycines & Gland cell & $191 / 4 \mathrm{e}-102$ \\
\hline G13* & 388 & DR159664 & CX530322.1 & Medicago truncatula & Root cell suspension culture & 229/2e-119 \\
\hline $\mathrm{G} 15^{*}$ & 643 & DR159665 & CB893436.1 & Medicago truncatula & 3-day-old seedling roots & $570 / 0.0$ \\
\hline G16 ${ }^{*}$ & 477 & DR159666 & BE324025.2 & Medicago truncatula & Phosphate-starved leaf & $419 / 0.0$ \\
\hline $\mathrm{G} 17^{*}$ & 526 & DR159667 & BG454790.1 & Medicago truncatula & Developing leaf & $448 / 0.0$ \\
\hline G18 & 118 & DR159668 & CX526702.1 & Medicago truncatula & Aphid-infected shoots & $70 / 2 \mathrm{e}-30$ \\
\hline G19* & 403 & DR159669 & AW287853.2 & Medicago truncatula & Phosphate-starved root & $328 / 0.0$ \\
\hline $\mathrm{G} 20^{*}$ & 511 & DR159670 & BF650554 & Medicago truncatula & $\begin{array}{l}\text { Cell cultures derived } \\
\text { from root tissues }\end{array}$ & $377 / 0.0$ \\
\hline $\mathrm{G} 21^{*}$ & 560 & DR159671 & CO513447.1 & Medicago sativa & Glandular trichomes & $316 / 1 \mathrm{e}-176$ \\
\hline $\mathrm{G} 22^{*}$ & 472 & DR159672 & CF069452.1 & Medicago truncatula & Various stages mixed tissues & $388 / 0.0$ \\
\hline G23 & 276 & DR159673 & CA920444.1 & Medicago truncatula & Various stages mixed tissues & $247 / 1 \mathrm{e}-135$ \\
\hline G24 & 253 & DR025670 & AJ847674 & Medicago truncatula & Whole roots & $61.9 / 3.8 \mathrm{e}-12$ \\
\hline $\mathrm{G} 25^{*}$ & 489 & DR159674 & CB891349.1 & Medicago truncatula & Seedling roots & $316 / 1 \mathrm{e}-176$ \\
\hline G26 & 148 & DR025671 & CX539620.1 & Medicago truncatula & Germinating seed & $27 / 3 e-05$ \\
\hline G27 & 278 & DR159675 & CO514116.1 & Medicago sativa & Glandular trichomes & $153 / 1 \mathrm{e}-79$ \\
\hline $\mathrm{G} 29^{*}$ & 537 & DR159676 & CA920444.1 & Medicago truncatula & Various stages mixed tissues & $329 / 0.0$ \\
\hline $\mathrm{G} 30^{*}$ & 690 & DR159677 & BG646644.1 & Medicago truncatula & 3-day-old seedling roots & $681 / 0.0$ \\
\hline G31 & 300 & DR159678 & DR107844.1 & Canis familiaris & Mixed & $332 / 0.0$ \\
\hline G33 & 83 & DR025673 & CB861201.1 & Hordeum vulgare & 1-day-old coleoptile & $66 / 3 e-28$ \\
\hline $\mathrm{G} 34^{*}$ & 352 & DR159680 & CB893273.1 & Medicago truncatula & 3-day-old seedling roots & $301 / 8 \mathrm{e}-168$ \\
\hline $\mathrm{G} 35^{*}$ & 533 & DR159681 & AL380616.1 & Medicago truncatula & Symbiotic root nodules & $263 / 6 e-145$ \\
\hline G36* & 314 & DR159682 & CB892026.1 & Medicago truncatula & Seedling roots & 247/1e-135 \\
\hline $\mathrm{G} 37^{*}$ & 523 & DR159683 & BI310237.1 & Medicago truncatula & Immature seeds & $493 / 0.0$ \\
\hline G1 & 66 & DR159661 & & & & \\
\hline G2 & 75 & DR025666 & & & & \\
\hline G14 & 162 & DR025669 & & & & \\
\hline G28 & 155 & DR025672 & & & & \\
\hline G32 & 68 & DR159679 & & & & \\
\hline
\end{tabular}

*The fragments were extended on the basis of GenBank data.

the cDNA-AFLP fragments did not show any significant change, 44 differentially expressed TDFs were detected. Thirty-seven differentially expressed fragments were ex- cised from the gels, re-amplified by PCR and sequenced. There were technical problems with sequencing the other seven fragments and thus they were not studied. Figure 1 
Table 3 AFLP, Northern blot and RT-PCR analyses of the differentially expressed TDFs in nifA mutant Sm1354 nodules at 30 days after inoculation

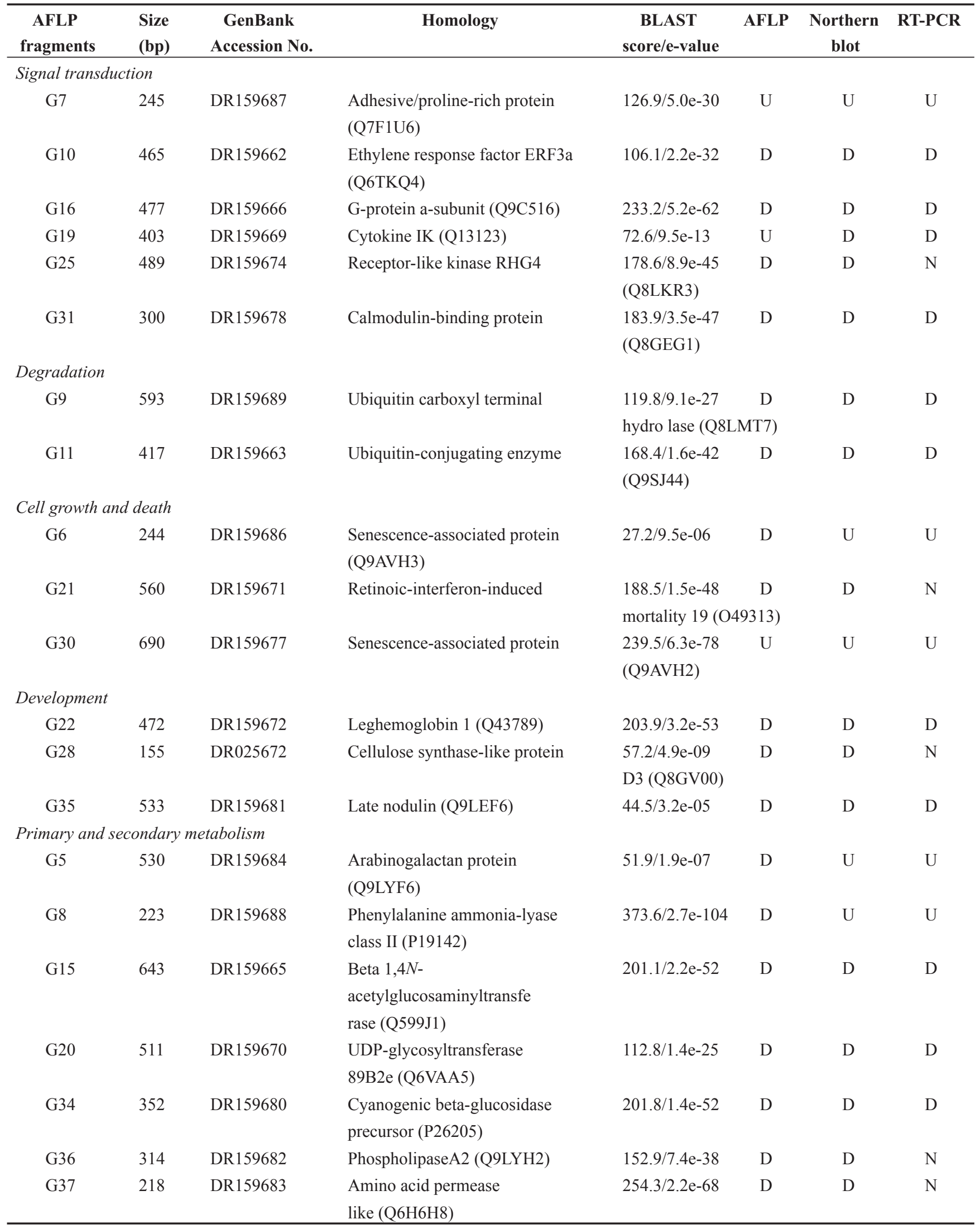


Table 3 AFLP, Northern blot and RT-PCR analyses of the differentially expressed TDFs in nifA mutant Sm1354 nodules at 30 days after inoculation (continued)

\begin{tabular}{|c|c|c|c|c|c|c|c|}
\hline $\begin{array}{l}\text { AFLP } \\
\text { fragments }\end{array}$ & $\begin{array}{l}\text { Size } \\
\text { (bp) }\end{array}$ & $\begin{array}{c}\text { GenBank } \\
\text { Accession No. }\end{array}$ & Homology & $\begin{array}{c}\text { BLAST } \\
\text { score/e-value }\end{array}$ & AFLP & $\begin{array}{c}\text { Northern } \\
\text { blot }\end{array}$ & RTPCR \\
\hline \multicolumn{8}{|c|}{ Unknown function protein } \\
\hline G17 & 526 & DR159667 & Hypothetical protein (Q9SU16) & $391.7 / 1.2 \mathrm{e}-111$ & $\mathrm{U}$ & $\mathrm{D}$ & $\mathrm{D}$ \\
\hline G23 & 276 & DR159673 & Hypothetical protein (Q8LEF8) & $247 / 1 \mathrm{e}-135$ & $\mathrm{U}$ & $\mathrm{D}$ & $\mathrm{D}$ \\
\hline G1 & 66 & DR159661 & & & $\mathrm{D}$ & $\mathrm{D}$ & $\mathrm{N}$ \\
\hline G2 & 75 & DR025666 & & & $\mathrm{D}$ & $\mathrm{D}$ & $\mathrm{N}$ \\
\hline G3 & 162 & DR025667 & & & $\mathrm{D}$ & $\mathrm{D}$ & $\mathrm{D}$ \\
\hline G4 & 412 & DR159684 & & & $\mathrm{D}$ & $\mathrm{D}$ & $\mathrm{N}$ \\
\hline $\mathrm{G} 24$ & 253 & DR025670 & & & $\mathrm{D}$ & $\mathrm{D}$ & $\mathrm{D}$ \\
\hline G26 & 148 & DR025671 & & & $\mathrm{U}$ & $\mathrm{D}$ & $\mathrm{D}$ \\
\hline $\mathrm{G} 27$ & 278 & DR159675 & & & $\mathrm{D}$ & $\mathrm{D}$ & $\mathrm{N}$ \\
\hline G32 & 68 & DR159679 & & & $\mathrm{D}$ & $\mathrm{D}$ & $\mathrm{N}$ \\
\hline G33 & 83 & DR025673 & & & $\mathrm{D}$ & D & $\mathrm{N}$ \\
\hline
\end{tabular}

$\mathrm{U}$, up regulated; $\mathrm{D}$, down regulated; $\mathrm{N}$, untested.

shows an example of a typical cDNA-AFLP banding pattern. Medicago sativa is a tetrasomic plant and its sequence information was limited. However, the database of the diploid plant Medicago truncatula provided reliable and sufficient information for sequence comparison. TDF fragments that were only 50-300 bp long were subsequently extended to $\sim 500 \mathrm{bp}$ for Northern and RT-PCR experiments, if homologous sequences were available in public databases (Table 2). The extended cDNA fragments were obtained by RT-PCR, and then cloned into pMD18-T for sequence analysis. Through BLAST analysis, TDFs were organized into several categories according to their putative functions, including primary and secondary metabolism, signal communication, protein degradation, cell growth and development (Table 3).

\section{Reverse Northern and RT-PCR verification}

To assess the results of cDNA-AFLP analysis, gene expression patterns were first verified by reverse Northern blot. The results from hybridization-based methods were not consistent with cDNA-AFLP, as only 28 TDFs (75.6\%) showed coincident expression patterns with those in AFLP experiments (Figure 2, Table 3). In order to confirm our results, RT-PCR was carried out on 24 TDFs, including all of the nine TDFs showing conflicting expression patterns between cDNA-AFLP and Northern blot results. All of the RT-PCR products were sequenced directly for verification. The results of 23 TDFs $(95.8 \%)$ in RT-PCR experiments were consistent with those from Northern blot analyses, whereas the remaining G12 was consistent with the result from cDNA-AFLP. This indicated that reverse Northern blot is more reliable than cDNA-AFLP (Figure 3 , Table 3).

Analysis of gene expression time series in nifA mutation nodules

The expression patterns of TDFs are dynamic in nodules. In Northern blots of the nodules 15 days after inoculation, the expression patterns of some TDFs differed from those 30 days after inoculation. Compared with wild-type nodules, the phospholipaseA2 (G36), receptor-like kinase (G25) and three unknown functional cDNA fragments (G3, G17, G18) showed no distinct difference in expression level in 15-day-old nifA mutant nodules. A senescence-related protein (G30) was down-regulated in 15-day nifA mutant nodules but up-regulated in 30-day nodules. In contrast, 13 TDFs (35\%) including one nodulin (G22) and the G-protein $\alpha$-subunit (G16) were up-regulated in 15-day nodules, and 
A

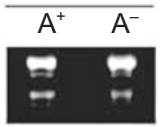

B

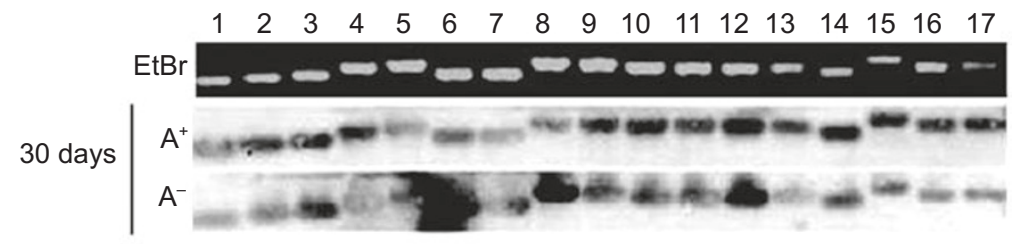

$\begin{array}{lllllllllllllllll}18 & 19 & 20 & 21 & 22 & 23 & 24 & 25 & 26 & 27 & 28 & 29 & 30 & 31 & 32 & 33 & 34\end{array}$
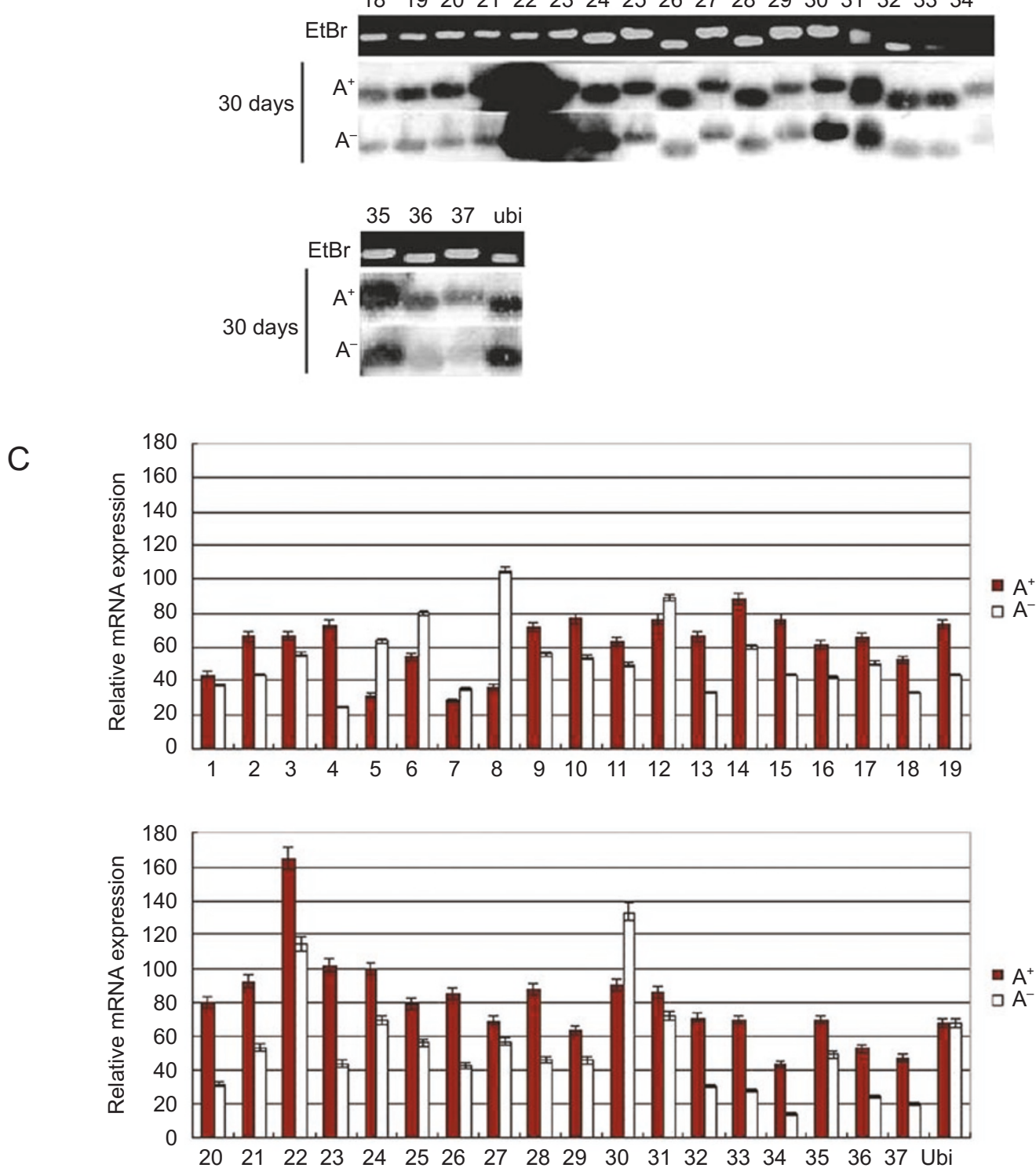

Figure 2 Reverse Northern blot analysis of TDFs. (A) Electropherogram of methanol denaturing gel electrophoresis of total RNA

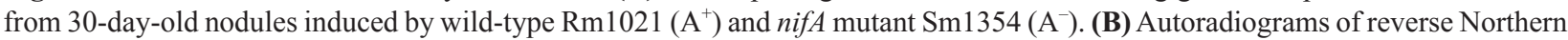
hybridization. The duplicate membranes were hybridized against total cDNA probes resulting from wild-type Rm1021 and Sm1354 nodules, separately. Upper part show agarose gel electrophoresis of the 37 amplified cDNA fragments stained with EtBr. (C) Quantification of mRNA expression levels. Bands in their intensities were quantified by scanning and normalized with ubiquitin control. The differences in expressions were determined by Student's $t$-test. $N=3, p<0.01$. 
A

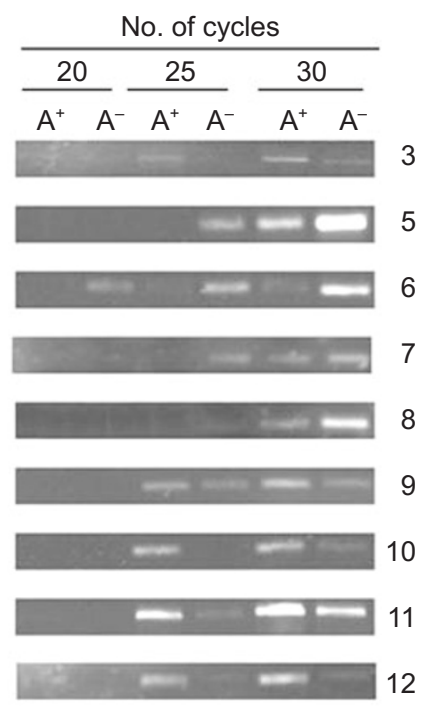

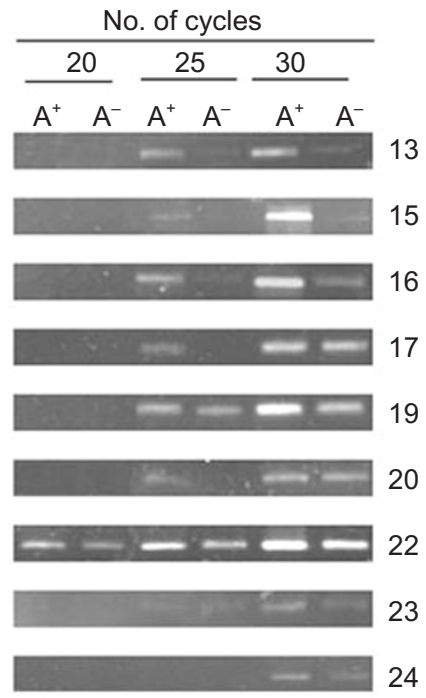

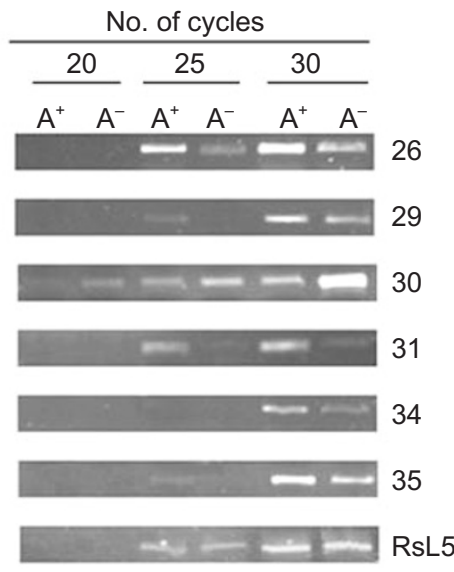

B

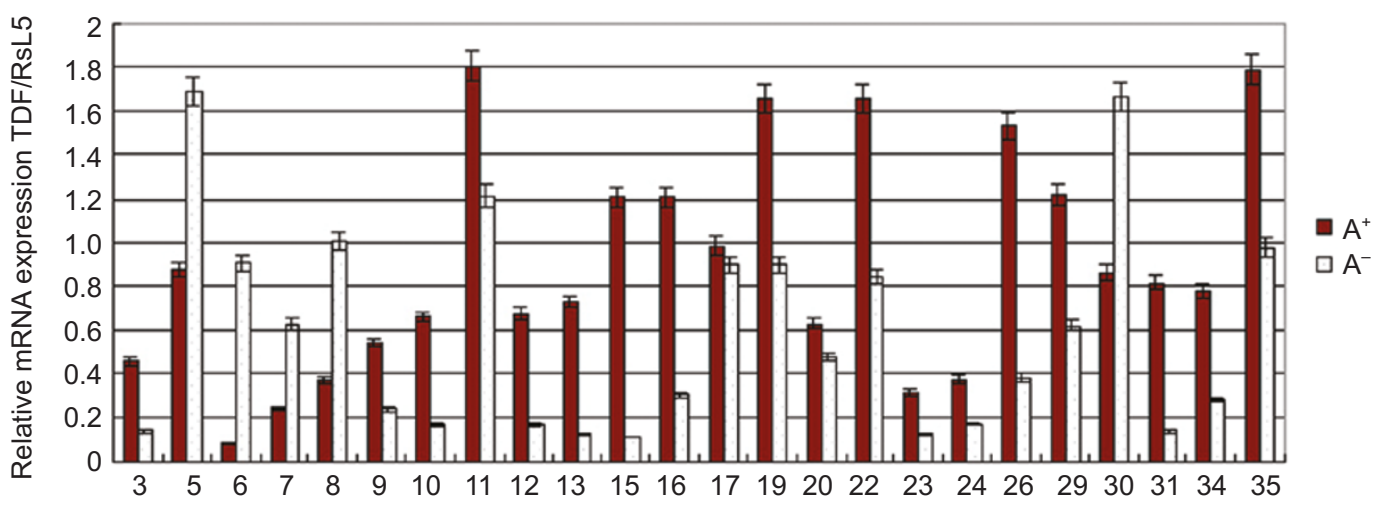

Figure 3 RT-PCR analysis of differentially expressed TDFs in 30-day-old nodules induced by wild-type Rm1021 (A ${ }^{+}$) and nifA mutant Sm1354 (A-). (A) Agarose gel electrophoresis of PCR productions. The expressions of 24 TDFs were checked at 20, 25 and 30 cycles. RsL5, ribosome large subunit gene, was used as control. (B) Quantification mRNA levels. Bands in their intensities were quantified by scanning. The differences in expression rates were determined by Student's $t$-test. $N=3, p<0.01$.

yet they were down-regulated at 30 days (Figure 4).

\section{Discussion}

The cDNA-AFLP technique is a reliable method for revealing small differences between close individuals, especially in non-sequenced organisms. Since its first application on potato tuber development, several modifications of this technique have improved its validity and advantages over other fingerprinting techniques and DNA chip-based approaches [18-20]. In most cases, it has been employed for surveying transcriptional changes in host plants during interactions with fungi, bacteria, nematode or environmental stimuli [21-29]. In this study, cDNA-AFLP was successfully used to identify 37 differentially expressed host plant genes in Alfalfa nodules.

Among the 37 TDFs obtained in this study, six were found to be related to signal transduction. The ethylene response factor contains a core sequence of GCC box, which is recognized by ethylene-responsive element-binding proteins to regulate ethylene responses via regulating gene transcription and expression [30-32]. Calmodulin is recognized as a major calcium sensor and orchestrator of regulatory events through its interaction with a diverse group of cellular proteins, including cytoskeletal elements, ion channels, kinases and phosphatases. [33-35]. In Arabidopsis and rice plants, a wide range of processes including seed germination, shoot and root growth, and stomatal regulation are altered by mutations in G-protein components [36-41]. In Alfalfa, G proteins mediate the nod 
A

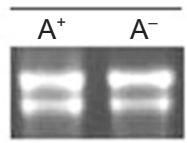

B
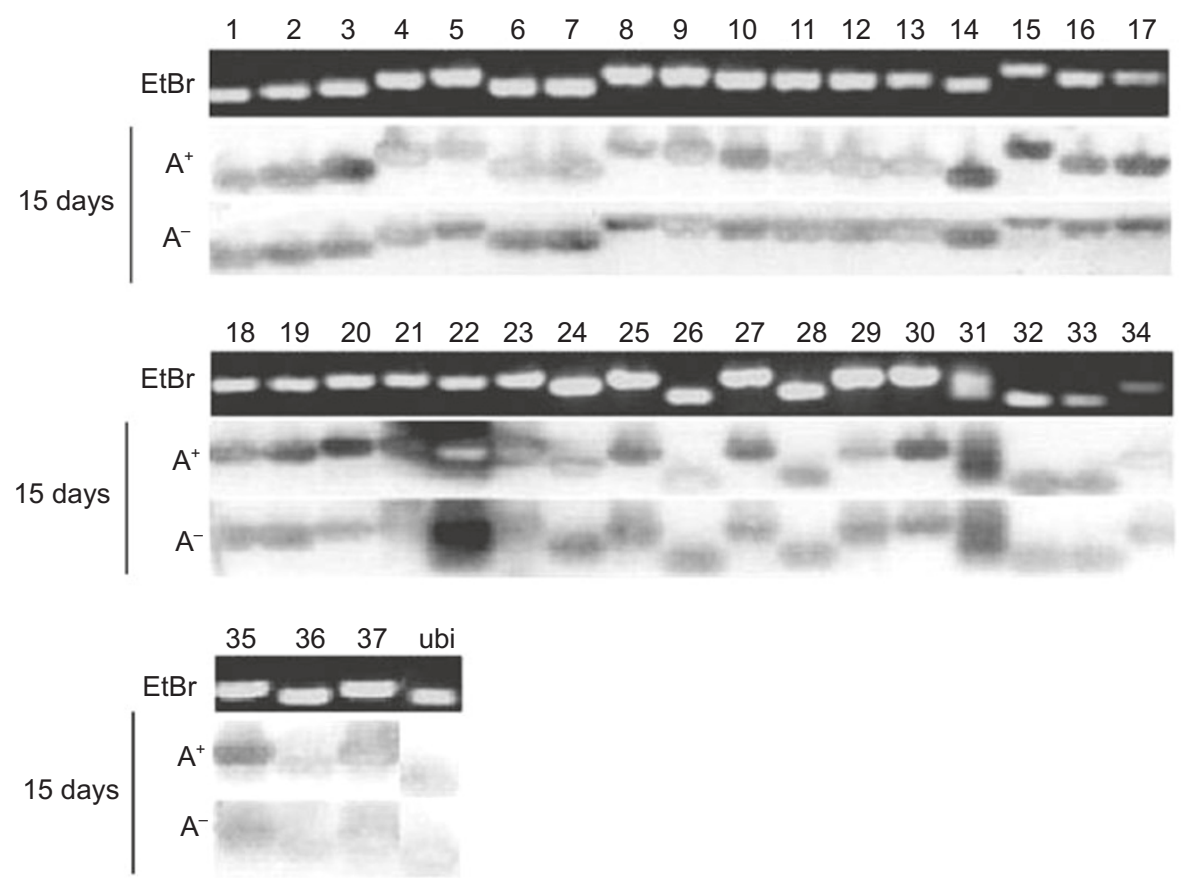

C
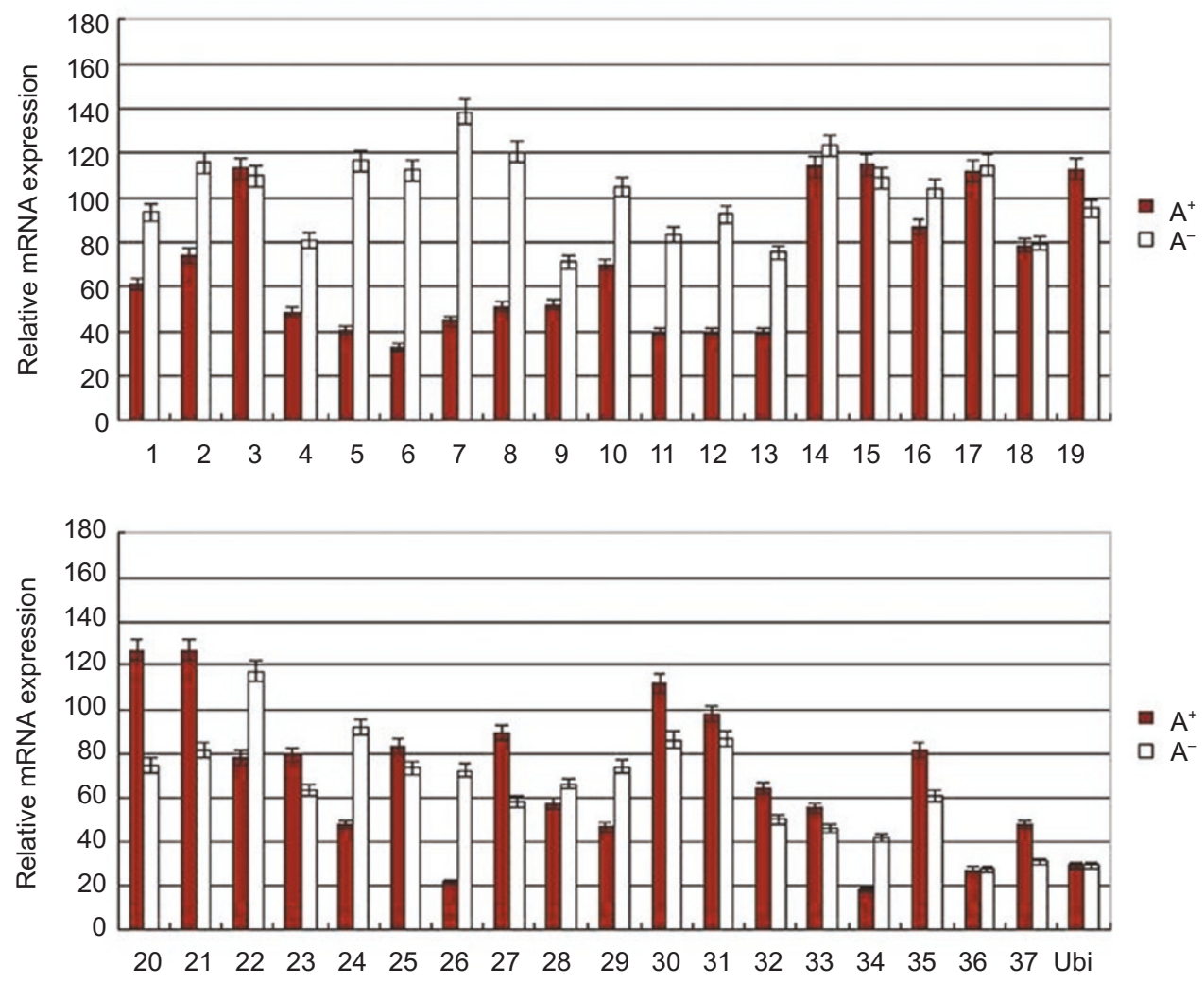

Figure 4 Same as Figure 2, except for 15-day-old nodules. 
factor signaling pathway during symbiosis [42]. However, expression patterns of up-regulated G-protein-coupled receptors (G7) and down-regulated G-protein $\alpha$-subunit (G16) indicate a complex regulation pattern of $G$ proteins in nodules. The retinoid-interferon-induced mortality-19 gene (GRIM-19) and cytokine IK are novel cell death regulators characterized only in animals [43-45]. Further studies on their homologous genes in plants may provide new insights into apoptotic plant cell death.

The ubiquitin/26S proteasome pathway is a major route for the selective degradation of cytoplasmic and nuclear proteins in eucaryotes [46, 47]. At least three enzymes are involved in this action - a ubiquitin-activating enzyme (E1), a ubiquitin-conjugating enzyme (E2) and a ubiquitin ligase (E3) - which work sequentially in a cascade [48, 49]. In the present study, one ubiquitin carboxyl terminal hydrolase and one ubiquitin-conjugating enzyme (E2) were down-regulated in 30-day nifA mutant nodules. This indicates that the elaborate regulation of protein is damaged to some degree in nifA mutant nodules. The effects of protein degradation are not well understood in legume nodules and further study is needed.

The nutrient exchange between Rhizobia and legume plants is executed by a number of genes including those involved in primary and secondary metabolism. In nif $A$ mutant bacteroids, a number of genes related to central intermediary metabolism are down-regulated in bacteroids 30 days after inoculation (unpublished data). In our study, seven host plant genes related to central intermediary metabolism were identified in S. meliloti nifA mutant nodules. Five genes were down-regulated in 30-day nifA mutant nodules, whereas the phenylalanine ammonialyase class II (G8) gene and arabinogalactan (G5) were up-regulated. PAL catalyses the non-oxidative deamination of L-phenylalanine to trans-cinnamic acid. This enzyme is ubiquitous in plants and is involved in the production of phenylpropanoids such as lignin and phytoalexins $[50,51]$. The amino-acid permease (G37) is an integral membrane protein involved in the transport of amino acids into the cell. A study of Saccharomyces cerevisiae found that the amino acid permease AGP1 is dependent on an ubiquitin ligase complex, suggesting that an ubiquitination step is required for amino acid signal transduction [52].

The nif $A$ gene exerts its pleiotropic nature in controlling further nodulation by eliciting host plant defense reactions at early stages in development [3]. In addition to the nif/fix genes, four nodulation-specific genes (nodH, nodL, nolF and $n o e B$ ) were down-regulated in 30-day nodules induced by the $S$. meliloti nifA mutant (unpublished data). In our study, two late nodulin genes (G22, G35) were found to be down-regulated in nif $A$ mutant nodules. In addition, the cellulose synthase-like protein D3 was also down-regu- lated. Its homologous gene in Arabidopsis is involved in biosynthesis of polysaccharides required during root hair elongation [53-55]. As root hair deformation is a defined procedure for nodule initiation, cellulose synthase-like protein D3 is likely to influence nodulation development. Considering our results together with previous findings, the data suggest that nodule development is affected by mutations of the S. meliloti nifA gene.

Although several molecular events taking place in nif $A$ mutants are illustrated in the present study, there are not enough data to fully understand the relationship between these molecular events and the nifA gene. Even though time-dependent gene expression was deduced from the expression patterns of 15 - and 30-day nodules, more studies are needed to elucidate the roles of these genes in nodule development.

\section{Acknowledgements}

This work was supported by grants from the National Basic Research program of China (973 Program, 2001CB108901), National Natural Science Foundation of China to Guan Qiao Yu (30170512) and National Natural Science Foundation of China to Hua Song Zou (30400267).

\section{References}

1 Beynon JL, Williams MK, Cannon FC. Expression and functional analysis of the Rhizobium meliloti nifA gene. EMBO J 1988; 7:7-14.

2 David M, Daveran ML, Batut J, et al. Cascade regulation of nif gene expression in Rhizobium meliloti. Cell 1988; 54:671-683.

3 Ficscher HM, Alvarez-Morales A, Hennecke H. The pleiotropic nature of symbiotic regulatory mutants: Bradyrhizobium japonicum nifA gene is involved in control of nif gene expression and formation of determinate symbiosis. EMBO J 1986; 5:11651173.

4 Halverson LJ, Stacey G. Signal exchange in plant-microbe interaction. Microbiol Rev 1986; 50:193-225.

5 Cohn J, Day RB, Stacey G. Legume nodule organgenesis. Trends Plant Sci 1998; 3:105-110.

6 Trevaskis B, Colebatch G, Desbrosses G, et al. Differentiation of plant cells during symbiotic nitrogen fixation. Comp Funct Genom 2002; 3:151-157.

7 Szczyglowski K, Amyot L. Symbiosis, inventiveness by recruitment? Plant Physiol 2003; 131:935-940.

8 Poole PS, Allaway D. Carbon and nitrogen metabolism in Rhizobium. Adv Microb Physiol 2000; 43:117-163.

9 Barnett MJ, Fisher RF, Jones T, et al. Nucleotide sequence and predicted functions of the entire Sinorhizobium meliloti $\mathrm{pSymA}$ megaplasmid. Proc Natl Acad Sci USA 2001; 98:9883-9888.

10 De Philip P, Batut J, Boistard P. Rhizobium meliloti FixL is an oxygen sensor and regulates $R$. meliloti nifA and fixK genes differently in Escherichia coli. J Bacteriol 1990; 172:4255-4262. 
11 Hertig C, Li RY, Louarn AM, et al. Rhizobium meliloti regulatory gene fixJ activates transcription of $R$. meliloti nifA and fixK genes in Escherichia coli. J Bacteriol 1989; 171:1736-1738.

12 Batut J, Daveran-Mingot ML, David M, et al. fixK, a gene homologous with $f n r$ and $c r p$ from Escherichia coli, regulates nitrogen fixation genes both positively and negatively in Rhizobium meliloti. EMBO J 1989; 8:1279-1286.

13 Fischer HM, Hennecke H. Direct response of Bradyrhizobium japonicum nifA-mediated nif gene regulation to cellular oxygen status. Mol Gen Genet 1987; 209:621-626.

14 Fischer HM. Genetic regulation of nitrogen fixation in Rhizobia. Microbiol Rev 1994; 58:352-386.

15 Hirsch AM, Smith CA. Effects of Rhizobium meliloti nif and fix mutants on alfalfa root nodule development. J Bacteriol 1987; 169:1137-1146.

$16 \mathrm{Wu}$ T, Zhu JB, Yu GQ, Shen SC. Inhibition of nodule development by multicopy promoters of Rhizobiun meliloti nif/fix genes. Sci China (C) 1995; 38:1108-1116.

17 Yang CT, Yu GQ, Shen SC, Zhu JB. Functional difference between Sinorhizobium meliloti NifA and Entrobacter cloacae NifA. Sci China (C) 2003; 33:398-404.

18 Bechem CWB, Oomen RJFJ, Visser RGF. Transcript imaging with cDNA-AFLP: a step by step protocol. Plant Mol Biol Rep 1998; 16:157-173.

19 Bechem CWB, Van der Hoeven RS, de Bruijin SM, et al. Visualization of differential gene expression using a novel method of RNA fingerprint based on AFLP: analysis of gene expression during potato tuber development. Plant J 1996; 9:745-753.

20 Reijans M, Lascaris R, Groenger AO, et al. Quantitative comparison of cDNA-AFLP, microarray, and GeneChip expression data in Saccharomyces cerevisiae. Genomics 2003; 82:606-618.

21 Durrant W, Rowland O, Piedras P, Hammond-Kosack KE, Jones JDG. cDNA-AFLP reveals a striking overlap in race specific resistance and wound response gene expression profiles. Plant Cell 2000; 12:963-977.

22 Carmona E, Vargas D, Borroto CJ, et al. cDNA-AFLP analysis of differential gene expression during the interaction between sugarcane and Puccinia melanocephala. Plant Breed 2004; 123:499-501.

23 Goupil P, Mahamoud YS, Poulain J, et al. cDNA-AFLP display for the isolation of differentially expressed genes during chicory root development. Plant Physiol 2003; 160:303-309.

24 Milioni D, Saado PE, Stacey NJ, Robert K, McCann MC. Early gene expression associated with the commitment and differentiation of a plant tracheary element is revealed by cDNA-amplified fragment length polymorphism analysis. Plant Cell 2002; 14:2813-2824.

25 Noëi L, Thieme F, Nennsitel D, Bonas U. cDNA-AFLP analysis unravels a genome-wide $h r p G$-regulon in the plant pathogen Xanthomonas campestris pv. vesicatoria. Mol Microbiol 2001; 41:1271-1281.

26 Qin L, Overmars H, Herder J, et al. An efficient cDNA-AFLPbased strategy for the identification of putative pathogenicity factors from the potato cyst nematode Globodera rostochiensis. Mol Plant Microbe Interact 2000; 8:830-836.

27 Simões-Araújo JL, Rodrigues RL, de A Gerhardt LB, et al. Identification of differentially expressed genes by cDNA-AFLP technique during heat stress in cowpea nodules. FEBS Lett 2002; 515:44-50.
28 Eckey C, Korell M, Leib K, et al. Identification of powdery mildew-induced barley genes by cDNA-AFLP: functional assessment of an early expressed MAP kinase. Plant Mol Biol 2004; 55:1-15.

29 De Paepe A, Vuylsteke M, Van Hummelen P, Zabeau M, Van Der Streaten D. Transcriptional profiling by cDNA-AFLP and microarray analysis reveals novel insights into the early response to ethylene in Arabidopsis. Plant J 2004; 39:537-559.

30 Berrocal-Lobo M, Molina A. Ethylene response factor 1 mediates Arabidopsis resistance to the soilborne fungus Fusarium oxysporum. Mol Plant Microbe Interact 2004; 17:763-770.

31 Guo HW, Ecker JR. The ethylene signaling pathway: new insights. Curr Opin Plant Biol 2004; 7:40-49.

32 Zhang HX, Zhu BZ, Yu BY, et al. Cloning and DNA-binding properties of ethylene response factor, LeERF1 and LeERF2, in tomato. Biotechnol Lett 2005; 27:423-428.

33 Lidwell K, Dillon J, Sihota A, Connor1VO, Pilkington B. Determining calmodulin binding to metabotropic glutamate receptors with distinct protein-interaction methods. Biochem Soc Trans 2004; 32:868-870.

34 Levy M, Wang Q, Kaspi R, Parrella MP, Abel S. Arabidopsis IQD1, a novel calmodulin-binding nuclear protein, stimulates glucosinolate accumulation and plant defense. Plant J 2005; 43:79-96.

35 Kim MC, Panstruga R, Elliott C, et al. Calmodulin interacts with MLO protein to regulate defense against mildew in barley. Nature 2002; 416:447-451.

36 Zeilinger S, Reithner B, Scala V, et al. Signal transduction by Tga3, a novel $\mathrm{G}$ protein alpha subunit of Trichoderma atroviride. Appl Environ Microbiol 2005; 71:1591-157.

37 Joo JH, Wang S, Che JG, Jones AM, Fedoroff NV. Different signaling and cell death roles of heterotrimeric $\mathrm{G}$ protein $\{\mathrm{alpha}\}$ and \{beta\} subunits in the Arabidopsis oxidative stress response to ozone. Plant Cell 2005; 17:957-970.

38 Attwood TK, Findlay JBC. Design of a discriminating fingerprint for $\mathrm{G}$ protein-coupled receptors. Protein Eng 1993; 6:167-176.

39 Attwood TK, Findlay JBC. Fingerprinting G protein-coupled receptors. Protein Eng 1994; 7:195-203.

40 Neer EJ. Heterotrimeric $G$ proteins: organizers of transmembrane signals. Cell 1995; 80:249-257.

41 Surya A, Stadel JM, Knox BE. Evidence for multiple, biochemically distinguishable states in the $\mathrm{G}$ protein-coupled receptor, rhodopsin. Trends Pharmacol Sci 1998; 19:243-247.

42 Pingret JL, Journet EP, Barker DG. Rhizobium Nod factor signaling: evidence for a $\mathrm{G}$ protein-mediated transduction mechanism. Plant Cell 1998; 10:659-671.

43 Chidambaram NV, Angell JE, Ling W, Hofmann ER, Kalvakolanu DV. Chromosomal localization of human GRIM-19, a novel IFN-beta and retinoic acid-activated regulator of cell death. J Interferon Cytokine Res 2000; 20:661-665.

$44 \mathrm{Hu}$ J, Angell JE, Zhang J, et al. Characterization of monoclonal antibodies against GRIM-19, a novel IFN-beta and retinoic acidactivated regulator of cell death. J Interferon Cytokine Res 2002; 22:1017-1026.

45 Krief P, Augery-Bourget Y, Plaisance S, et al. A new cytokine (IK) down-regulating HLA class II: monoclonal antibodies, cloning and chromosome localization. Oncogene 1994; 9:3449-3456.

46 Vierstra RD. The ubiquitin/26S proteasome pathway, the complex last chapter in the life of many plant proteins. Trends Plant Sci 
2003; 8:135-142.

47 Doelling DH, Yan N, Kurepa J, Walker J, Vierstra RD. The ubiquitin-specific protease $U B P 14$ is essential for early embryo development in Arabidopsis thaliana. Plant J 2001; 27:393405.

48 Hellmann H, Estelle M. Plant development: regulation by protein degradation. Science 2002; 297:793-797.

49 Bachamir A, Novatchkova M, Potuschak T, Eisenhaber F. Ubiquitylation in plants: a postgenomic look at a post-translational modification. Trends Plant Sci 2001; 6:463-470.

50 Williams JS, Thomas M, Clarke DJ. The gene stlA encodes a phenylalanine ammonia-lyase that is involved in the production of a stilbene antibiotic in Photorhabdus luminescens TT01. Microbiol 2005; 151:2543-2550.

51 Savouré A, Sallaud C, Ei-Turk J, et al. Distinct response of
Medicago suspension cultures and roots to Nod factors and chitin oligomers in the elicitation of defense-related responses. Plant J 1997; 11:277-287.

52 Bernard F, Andre B. Ubiquitin and the SCFGrr 1 ubiquitin ligase complex are involved in the signalling pathway activated by external amino acids in Saccharomyces cerevisiae. FEBS Lett 2001; 496:81-85.

53 Favery B, Ryan E, Foreman J, et al. KOJAK encodes a cellulose synthase-like protein required for root hair cell morphogenesis in Arabidopsis. Gen Dev 2001; 15:79-89.

54 Saxena IM, Brown RM Jr. Cellulose biosynthesis: current views and evolving concepts. Ann Bot 2005; 96:9-21.

55 Kalluri UC, Joshi CP. Differential expression patterns of two cellulose synthase genes are associated with primary and secondary cell wall development in aspen trees. Planta 2004; 220:47-55. 